\title{
Assessment Awareness of Public About Breast Cancer and its Screening Measurements in Asir Region, KSA
}

\author{
Safar M. Alshahrani ${ }^{1}$ - Khalid A. Fayi ${ }^{1}$ - Saeed H. Alshahrani ${ }^{1}$ - Dhafer S. Alahmari ${ }^{1} \cdot$ Khaled M. Al Bejadi $^{1}$. \\ Dhafer M. Alahmari ${ }^{1}$ • Talal M. Alshahrani ${ }^{1}$ • Motaz N. Alsharif ${ }^{2}$
}

Received: 5 December 2018 / Accepted: 3 March 2019 / Published online: 15 March 2019

(C) Indian Association of Surgical Oncology 2019, corrected publication 2019

\begin{abstract}
Breast cancer (BC) has a major impact on women's health worldwide. The Kingdom of Saudi Arabia is no exception, where it is considered the most common malignancy, embodying the second leading cause of cancer deaths after lung cancer. In today's world, people are more health conscious and more aware of different medical specialties. Despite the tremendous advancements in education, there seems to be a limited knowledge among the public regarding this issue. Various studies have been conducted in many regions to determine the perception/awareness about breast cancer. The present study is of the first of its type in our region, assessing the awareness of the public about breast cancer and its screening measurements. As per our knowledge, there is no study that estimated the awareness of breast cancer and its screening measurements among the public in the Asir region. Therefore, this study aims to estimate the awareness of breast cancer and its screening measurements among public and assess the knowledge about Breast Self-Examination (BSE) and their opinion about its effectiveness in early diagnosis of breast cancer to detect the relationship between awareness and socioeconomic status. This study is a cross-sectional prospective study, with a sample of 1046 participants aged between 12 and 80 years (male and female) from the Asir region evaluated by questionnaire after attaining consent. The selection of participants was based on the simple random sampling method. The majority of participants were of age 20 to less than 30 years $(56.9 \%)$. About half of them were males $(52.7 \%)$. The majority was single (61.2\%). Most of them (74.0\%) have a high education level (University and more). About one-third of the participants (32.7\%) worked in the medical field, and most of them worked in the non-medical field (46.6\%). Regarding general knowledge, the score was $60.2 \%$, which represented a relatively good knowledge. The overall knowledge regarding breast cancer as recorded by our population reported that only $18.8 \%$ had good knowledge. Participants of this resettlement colony have poor knowledge about breast cancer, be it about risk factors, signs, and symptoms, or early detection procedures, where the overall knowledge score was only $18.8 \%$.
\end{abstract}

Keywords Breast Cancer $\cdot$ Awareness $\cdot$ Assessment $\cdot$ Knowledge $\cdot$ Breast self-examination $\cdot$ Screening $\cdot$ Asir Region $\cdot$ Saudi Arabia

\section{Introduction}

Breast cancer (BC) is a serious disease and a leading cause of deaths among females worldwide [1]. Approximately 1.67 million new cases of breast cancer, representing $25 \%$ of all

Safar M. Alshahrani

hasanalajh@gmail.com

1 College of Medicine, King Khalid University, Abha 61411, Saudi Arabia

2 Department of General Surgery, Assir Central Hospital, Abha, Saudi Arabia cancers, were diagnosed among women in 2012 [2]. Its incidence is the highest in developed countries, with rates as high as 92 per 100,000 people in North America compared with 27 per 100,000 people in Middle Africa and Eastern Asia [2].

In 2010, breast cancer was the ninth leading cause of death for females in the Kingdom of Saudi Arabia (KSA) [3, 4]. Moreover, 1308 new breast cancer cases were reported in 2009 , and about $25 \%$ of all new cancer cases were registered among Saudi women [5]. The incidence of breast cancer, it is expected, will increase in the coming decades in KSA due to the population's growth and aging [6].

A breast lump, one of the most common presentations of breast lesion, can be detected through breast self-examination 
Table 1 Personal and family data of general population participants from the Asir region, Saudi Arabia, 2018

\begin{tabular}{|c|c|c|c|}
\hline Personal data & & No. & $\%$ \\
\hline \multirow[t]{4}{*}{ Age in years } & $<20$ years & 124 & 11.9 \\
\hline & $20-$ & 595 & 56.9 \\
\hline & $30-$ & 168 & 16.1 \\
\hline & $40+$ & 159 & 15.2 \\
\hline \multirow[t]{2}{*}{ Gender } & Male & 551 & 52.7 \\
\hline & Female & 495 & 47.3 \\
\hline \multirow[t]{3}{*}{ Marital status } & Single & 639 & 61.1 \\
\hline & Married & 391 & 37.4 \\
\hline & Divorced/widow & 16 & 1.5 \\
\hline \multirow[t]{2}{*}{ Educational level } & Below university & 272 & 26.0 \\
\hline & University/more & 774 & 74.0 \\
\hline \multirow[t]{3}{*}{ Work field } & Not working & 217 & 20.7 \\
\hline & Non-medical field & 487 & 46.6 \\
\hline & Medical field & 342 & 32.7 \\
\hline \multirow[t]{2}{*}{ Nationality } & Saudi & 1031 & 98.6 \\
\hline & Non-Saudi & 15 & 1.4 \\
\hline \multirow[t]{4}{*}{ Monthly income } & Less than 5000 S.R & 199 & 19.0 \\
\hline & $5000-15,000$ S.R & 543 & 51.9 \\
\hline & $15,000-30,000$ S.R & 243 & 23.2 \\
\hline & More than 30,000 S.R & 61 & 5.8 \\
\hline \multirow[t]{2}{*}{ History of breast cancer } & Yes & 11 & 1.1 \\
\hline & No & 1035 & 98.9 \\
\hline \multirow[t]{2}{*}{ Family history of breast cancer } & Yes & 140 & 13.4 \\
\hline & No & 906 & 86.6 \\
\hline
\end{tabular}

(BSE), clinical breast examination (CBE), and mammography. Early detection and prompt treatment offer the greatest chance of long-term survival in breast cancer patients [7, 8]. Mammography, CBE, and BSE are the secondary preventive methods used for screening in the early detection of breast cancer [7]. Cancer-screening tests play a pivotal role in reducing breast cancer-related mortalities [7]. The American Cancer Society (ACS) recommends CBE and mammography for the early detection of breast cancer [9]. According to ACS recommendations, women should know how their breasts normally feel and report any changes promptly to their health care providers. BSE is an option for women starting from the early $20 \mathrm{~s}$ [7, 9-11].

Many women miss early detection and treatment opportunities owing to lack of information, knowledge, breast cancer awareness, and cancer-screening practices [12]. A significant number of women have advanced stages of the disease due to lack of information, knowledge, and awareness of early detection measures. Two previous studies showed limited knowledge about breast cancer screening, and few women performed screening for early detection purposes [13-15].

This study aims to assess breast cancer knowledge, beliefs, and practices among Saudi women and men related to (i) disease-associated risk factors, (ii) causes (including myths and folklore), (iii) early detection, and (iv) existing and preferred sources of information. The ultimate goal of the work is to inform the development of effective breast cancer educational resources for Saudi women aimed at removing barriers to evidence-based prevention and early detection interventions. Hence, we undertook this study with an aim to ascertain awareness among the public about breast cancer.

\section{Materials and Methods}

This study is a cross-sectional prospective study, with a sample of 1046 participants aged between 12 and 80 years (male and female) from the Asir region evaluated by a questionnaire after taking their consent. The participants were selected based on the simple random sampling method. The consent form was given to participants after the purpose and method of the study was explained to each one of them. Participants who refused were excluded. We invited them to participate in a 31-question survey to assess their attitude, knowledge, perception, and understanding of breast cancer and its screening measurements. The information sought in the questionnaire also included demographics
Table 2 Breast cancer knowledge domains as recorded by the general population in the Asir region, Saudi Arabia, 2018

\begin{tabular}{lllllll}
\hline Knowledge domain & \multicolumn{2}{l}{ Poor } & & \multicolumn{2}{l}{ Good } & \multirow{2}{*}{ Score (\%) } \\
\cline { 2 - 3 } & No. & $\%$ & & No. & $\%$ & \\
\hline General knowledge & 592 & $56.6 \%$ & & 454 & 43.4 & 60.2 \\
Knowledge about signs and symptoms & 539 & $51.5 \%$ & & 507 & 48.5 & 51.4 \\
Knowledge about risk factors & 944 & $90.2 \%$ & & 102 & 9.8 & 31.8 \\
Knowledge about BSE & 688 & $65.8 \%$ & & 358 & 34.2 & 49.8 \\
\hline
\end{tabular}

Poor: score $\%<60 \%$.

Good: score \% 60-100\%.

$B S E$ breast self-examination. 


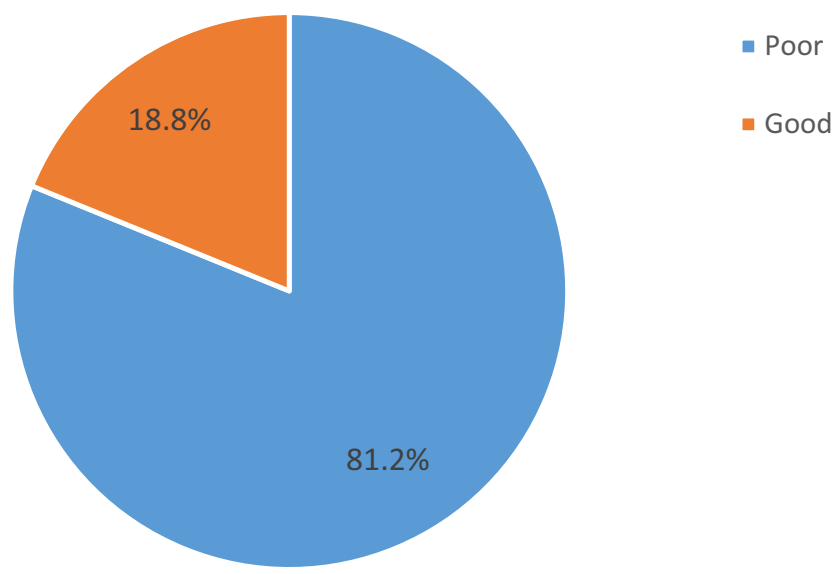

Fig. 1 Overall knowledge regarding breast cancer as recorded by the general population in the Asir region, Saudi Arabia, 2018

of the participants. The personal information about the students was kept confidential. The study was performed from Nov. 2018 to Mar. 2019. The study protocol was approved by the Ethics Committee of King Khalid University, and this research did not receive any specific grant from funding agencies in the public, commercial, or not-for-profit sectors.

\section{Statistical Analysis}

The collected data was revised, coded, and fed to the statistical software IBM SPSS version 20. The given graphs were constructed using Microsoft Excel. All statistical analysis was done using two-tailed tests and with an alpha error of 0.05 . A $p$ value less than or equal to 0.05 was considered to be statistically significant. For knowledge domains, each correct answer was given one point score, and the total domain score was assessed by summing the discrete scores for each item. The score was then transferred into score percent of maximum by dividing over the total score and multiplying it by 100 . The score percentage was then categorized into poor level if it was less than $60 \%$ of the maximum score and good if more. Chisquare/Mont Carlo exact test and Fisher's exact test were used to test for the association between different patients' factors and knowledge level. Exact tests were used if there were small frequencies where chi-square was invalid. Multiple logistic regression models were used to estimate the adjusted effect of different participants' data on their knowledge level.
Table 3 Distribution of breast cancer knowledge of the general population by their personal and family data, Asir region, Saudi Arabia, 2018

\begin{tabular}{|c|c|c|c|c|c|c|}
\hline \multirow[t]{3}{*}{ Factors } & & \multicolumn{4}{|c|}{ Overall knowledge } & \multirow[t]{3}{*}{$p$} \\
\hline & & \multicolumn{2}{|c|}{ Poor } & \multicolumn{2}{|c|}{ Good } & \\
\hline & & No. & $\%$ & No. & $\%$ & \\
\hline \multirow[t]{4}{*}{ Age in years } & $<20$ years & 114 & 91.9 & 10 & 8.1 & \multirow[t]{4}{*}{$.001 *$} \\
\hline & $20-$ & 448 & 75.3 & 147 & 24.7 & \\
\hline & $30-$ & 147 & 87.5 & 21 & 12.5 & \\
\hline & $40+$ & 140 & 88.1 & 19 & 11.9 & \\
\hline \multirow[t]{2}{*}{ Gender } & Male & 467 & 84.8 & 84 & 15.2 & \multirow[t]{2}{*}{$.002 *$} \\
\hline & Female & 382 & 77.2 & 113 & 22.8 & \\
\hline \multirow[t]{3}{*}{ Marital status } & Single & 508 & 79.5 & 131 & 20.5 & \multirow[t]{3}{*}{.208} \\
\hline & Married & 327 & 83.6 & 64 & 16.4 & \\
\hline & Divorced/widow & 14 & 87.5 & 2 & 12.5 & \\
\hline \multirow[t]{2}{*}{ Educational level } & Below university & 238 & 87.5 & 34 & 12.5 & \multirow[t]{2}{*}{$.002 *$} \\
\hline & University/more & 611 & 78.9 & 163 & 21.1 & \\
\hline \multirow[t]{3}{*}{ Work field } & Not working & 180 & 82.9 & 37 & 17.1 & \multirow[t]{3}{*}{$.001 *$} \\
\hline & Non-medical field & 426 & 87.5 & 61 & 12.5 & \\
\hline & Medical field & 243 & 71.1 & 99 & 28.9 & \\
\hline \multirow[t]{4}{*}{ Monthly income } & less than 5000 S.R & 172 & 86.4 & 27 & 13.6 & \multirow[t]{4}{*}{$.018^{*}$} \\
\hline & 5000-15,000 S.R & 446 & 82.1 & 97 & 17.9 & \\
\hline & $15,000-30,000$ S.R & 187 & 77.0 & 56 & 23.0 & \\
\hline & More than 30,000 S.R & 44 & 72.1 & 17 & 27.9 & \\
\hline \multirow[t]{2}{*}{ History of breast cancer } & Yes & 8 & 72.7 & 3 & 27.3 & \multirow[t]{2}{*}{${ }^{\mathrm{FE}} \mathrm{P}=.472$} \\
\hline & No & 841 & 81.3 & 194 & 18.7 & \\
\hline \multirow[t]{2}{*}{ Family history of breast cancer } & Yes & 106 & 75.7 & 34 & 24.3 & \multirow[t]{2}{*}{.076} \\
\hline & No & 743 & 82.0 & 163 & 18.0 & \\
\hline
\end{tabular}

$P$ Pearson $\chi^{2}$ test, FEP Fisher exact probability

$* p<0.05$ (significant) 
Table 4 Multiple logistic regression model for predictors of breast cancer knowledge among the general population in the Asir region, Saudi Arabia, 2018

\begin{tabular}{|c|c|c|c|c|c|c|}
\hline \multirow[t]{2}{*}{ Factor } & \multirow[t]{2}{*}{$B$} & \multirow[t]{2}{*}{$\mathrm{SE}$} & \multirow[t]{2}{*}{$P$} & \multirow[t]{2}{*}{ AOR } & \multicolumn{2}{|c|}{$95 \%$ C.I. for OR } \\
\hline & & & & & Lower & Upper \\
\hline Age in years & -.267 & .144 & .064 & .766 & .58 & 1.02 \\
\hline Female & 1.013 & .185 & .000 & 2.76 & 1.92 & 3.96 \\
\hline Married & .111 & .254 & .661 & 1.12 & .68 & 1.8 \\
\hline High education & .089 & .043 & .040 & 1.09 & 1.01 & 1.19 \\
\hline Medical field work & .666 & .141 & .000 & 1.95 & 1.48 & 2.56 \\
\hline Income & .249 & .104 & .017 & 1.28 & 1.05 & 1.57 \\
\hline History of BC & .785 & .727 & .281 & 2.17 & 0.52 & 9.09 \\
\hline Family history of $\mathrm{BC}$ & .389 & .228 & .088 & 2.33 & 0.94 & 2.42 \\
\hline Constant & -2.696 & 1.536 & .079 & .068 & & \\
\hline Model pseudo $R^{2}$; significance & \multicolumn{6}{|c|}{$12.3 \% ; .003 *$} \\
\hline Model fit & \multicolumn{6}{|l|}{$81.5 \%$} \\
\hline
\end{tabular}

$S E$ standard error, $A O R$ adjusted odds ratio, $C I$ confidence interval

\section{Results}

Table 1 shows the distribution of 1046 participants according to some of their socio-demographic characteristics. The majority of them were of age 20 to less than 30 years (56.9\%). About half of them were males (52.7\%). The majority was single (61.2\%). Most of them $(74.0 \%)$ have a high education level (University and more). About one-third (32.7\%) worked in the medical field, and most of them worked in non-medical fields (46.6\%). Approximately, all of them were from Saudi (98.6\%), and one-half belonged to intermediate monthly income families of 5000-15,000 Saudi Riyals (51.9\%). Almost all of them have no breast cancer history (98.1\%). Breast cancer in their family history was reported by $13.4 \%$ of the participants.

Table 2 shows the distribution of participants according to knowledge and BSE issues of breast cancer. Regarding general knowledge, the score was $60.2 \%$, representing a relatively good knowledge. With regard to knowledge of signs and symptoms, risk factors, and BSE. The scores were $51.4 \%$, $31.8 \%$, and $49.8 \%$ respectively, reflecting poor knowledge.

Fig. 1 illustrates the overall knowledge regarding breast cancer as recorded by our population; as reported, only $18.8 \%$ had good knowledge.

The associations between socio-demographic characteristics and $\mathrm{BC}$ knowledge scores are illustrated in Table 3. Knowledge of $\mathrm{BC}$ was significantly associated with age, gender, educational level, the field of work, and monthly income ( $p$ value $=0.001,0.002,0.002,0.001$, and 0.018 respectively). The good knowledge scores were lowest among participants whose age was less than 20 years $(8.1 \%)$, male gender (15.2\%), participants with below university educational level (12.5\%), non-medical field workers (12.5\%), and participants whose income was less than 5000 SR (13.6\%). Conversely, the good knowledge scores were highest among participants of age 20 to less than 30 years $(27.4 \%)$, female gender
Fig. 2 Sources of breast cancer knowledge among the general population in the Asir region, Saudi Arabia, 2018

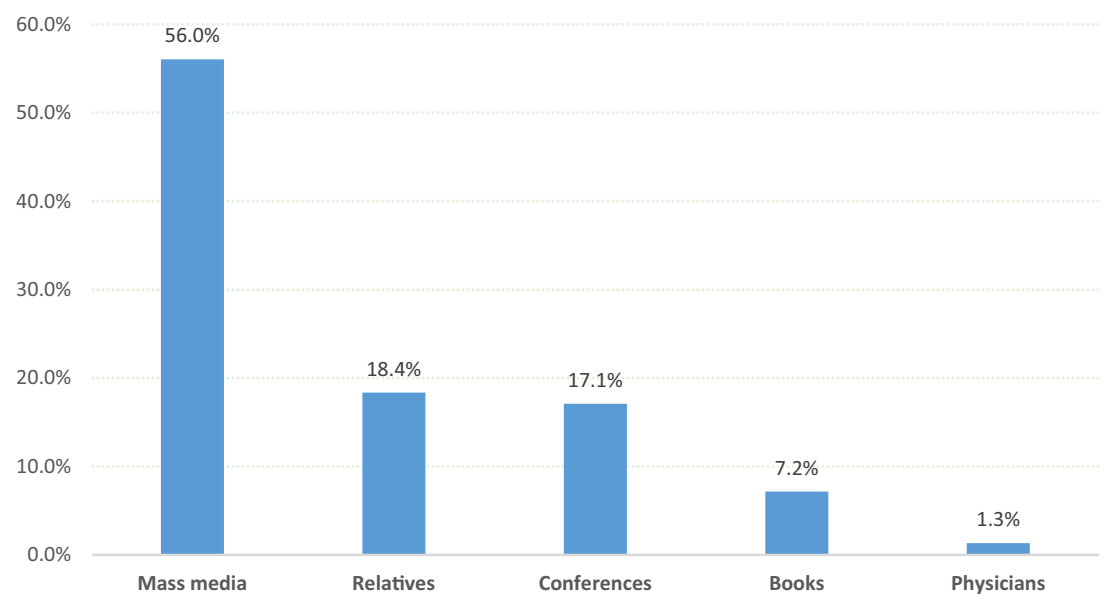

Source of knowledge 
Table 5 Breast selfexamination practice recorded among the general population in the Asir region, Saudi Arabia, 2018

\begin{tabular}{lcc}
\hline Practice regarding BSE & No. & $\%$ \\
\hline Previously undergone BSE & & \\
Yes & 260 & 52.5 \\
No & 235 & 47.5 \\
If yes, frequency $(n=260)$ & & \\
Rarely & 103 & 39.6 \\
Sometimes & 101 & 38.8 \\
Weekly & 11 & 4.2 \\
Monthly & 45 & 17.3 \\
Did you find breast changes $(n=260)$ \\
Yes & 37 & 14.2 \\
No & 223 & 85.8 \\
\hline
\end{tabular}

$B S E$ breast self-examination

(22.8\%), participants with university or more educational level $(21.1 \%)$, medical field workers $(28.9 \%)$, and participants whose income was more than 30,000 SR (27.9\%).

Table 4 shows the logistic regression analysis of breast cancer knowledge among participants with some independent variables. After adjusting for all possible confounders, the significant predictors to breast cancer were found to be positive females $(p=0.000)$, high education $(p=0.040)$, medical field workers $(p=0.000)$, income $(p=0.017)$, and lower PMS of barrier domain $(p=0.046)$.

Regarding sources of BC knowledge among our population, more than half of them received their knowledge from mass media, $18.4 \%$ from relatives, $17.1 \%$ from conferences, $7.2 \%$ from books, and $1.3 \%$ from physicians (Fig. 2).

Table 5 shows the BSE practice recorded among our population. About half of the participants $(52.5 \%)$ had previously undergone BSE. Regarding the frequency of BSE among participants who had undergone it, only $4.2 \%$ had undergone it weekly, and $17.3 \%$ monthly; the remaining were varied nearly equally between rarely and sometimes $(39.6 \%$ and $38.8 \%$ respectively). Among those who had undergone BSE, 14.2\% found changes in their breast.

Regarding risk factor awareness among our population, the following factors were thought to have risk for occurrence of BC: advancing age (56.1\%), exposure to radiation (39.3\%), avoiding breastfeeding (57.6\%), previous precancerous lesion on breast (49.4\%), old primipara (above age of 30 years) $(60.0 \%)$, breast injuries (40.5\%), late menopause (42.4\%), obesity (47.2\%), smoking (34.3\%), wearing of tight brassiere $(50.2 \%)$, inactivity and sedentary lifestyle $(39.7 \%)$, and underweight (47.4\%) (Table 6).

Table 7 illustrates the level of general knowledge among our population. Almost all of them (95.8\%) had heard of breast cancer. Most of them (59.8\%) thought that breast cancer was somewhat prevalent and $12.0 \%$ thought breast cancer for once prevent subsequent cancer.
Table 6 Risk factor awareness among the general population in the Asir region, Saudi Arabia, 2018

\begin{tabular}{|c|c|c|c|c|c|c|}
\hline & \multicolumn{2}{|l|}{ Yes } & \multicolumn{2}{|l|}{ No } & \multicolumn{2}{|c|}{ Do not know } \\
\hline & Count & Row $N \%$ & Count & Row $N \%$ & Count & Row $N \%$ \\
\hline Positive family history & 139 & 13.3 & 331 & 31.6 & 576 & 55.1 \\
\hline Advancing age & 587 & 56.1 & 257 & 24.6 & 202 & 19.3 \\
\hline Race/ethnicity & 310 & 29.6 & 417 & 39.9 & 319 & 30.5 \\
\hline Exposure to radiation & 411 & 39.3 & 294 & 28.1 & 341 & 32.6 \\
\hline Avoiding breast feeding & 603 & 57.6 & 158 & 15.1 & 285 & 27.2 \\
\hline Previous precancerous lesion on breast & 517 & 49.4 & 223 & 21.3 & 306 & 29.3 \\
\hline Old primipara (above age of 30 years) & 628 & 60.0 & 100 & 9.6 & 318 & 30.4 \\
\hline Multiparity and gravidity & 203 & 19.4 & 342 & 32.7 & 501 & 47.9 \\
\hline Null parity & 118 & 11.3 & 534 & 51.1 & 394 & 37.7 \\
\hline Early menarche (below age of 11 years) & 174 & 16.6 & 430 & 41.1 & 442 & 42.3 \\
\hline Recurrent oral contraceptives use & 158 & 15.1 & 375 & 35.9 & 513 & 49.0 \\
\hline Breast injuries & 424 & 40.5 & 164 & 15.7 & 458 & 43.8 \\
\hline Late menopause & 443 & 42.4 & 196 & 18.7 & 407 & 38.9 \\
\hline Hormonal replacement therapy & 228 & 21.8 & 319 & 30.5 & 499 & 47.7 \\
\hline Obesity & 494 & 47.2 & 128 & 12.2 & 424 & 40.5 \\
\hline Smoking & 359 & 34.3 & 239 & 22.8 & 448 & 42.8 \\
\hline Wearing of tight brassiere & 525 & 50.2 & 189 & 18.1 & 332 & 31.7 \\
\hline Inactivity and sedentary lifestyle & 415 & 39.7 & 238 & 22.8 & 393 & 37.6 \\
\hline Witchcraft & 281 & 26.9 & 304 & 29.1 & 461 & 44.1 \\
\hline Underweight & 496 & 47.4 & 247 & 23.6 & 303 & 29.0 \\
\hline
\end{tabular}


Table 7 General knowledge among the general population in the Asir region, Saudi Arabia, 2018

\begin{tabular}{llll}
\hline & & Count & Column $N \%$ \\
\hline Have you heard of breast cancer? & Yes & 1002 & 95.8 \\
& No & 44 & 4.2 \\
What do you think about breast cancer? & Rare & 52 & 5.0 \\
& Somewhat prevalent & 625 & 59.8 \\
Breast cancer for once prevent subsequent cancer & Highly prevalent & 369 & 35.3 \\
& Yes & 125 & 12.0 \\
& No & 447 & 42.7 \\
& Do not know & 474 & 45.3 \\
\hline
\end{tabular}

\section{Discussion}

According to this study, $95.9 \%$ of its participants had heard about breast cancer. This is higher than the percentage observed in a group of Ghana [16], Malaysian [17], and Iranian [18] women: $95 \%, 81.2 \%$, and $64 \%$ respectively. It is, however, much lower than the $100 \%$ among the female medical students in Harar, Ethiopia [19], and the 98.7\% among the female students in the University of Ibadan, Nigeria [20].

Knowledge and awareness of early detection measures of breast cancer, such as the BSE, is also considerable. About half of the participants, as shown by the findings, knew about BSE as an early detection measure, but very few participants practiced it. This results differed from Somdatta et al. [21], results which reported that knowledge and awareness of BSE are low and only a few women practiced it.

Our findings reveal poor understanding and misperceptions of the risk factors for breast cancer. More than half of the respondents identified advancing age, avoiding breastfeeding, old primipara (above age of 30 years), and wearing tight brassier as potential risk factors, while more than one-third identified exposure to radiation, previous precancerous lesion on breast, breast injuries, late menopause, obesity, smoking, inactivity, sedentary lifestyle, and underweight as potential risk factors for breast cancer. Only less than one-third of them identified positive family history, race/ethnicity, multiparity and gravidity, null parity, early menarche (below the age of 11 years), recurrent oral contraceptives use, hormonal replacement therapy, and witchcraft as potential risk factors of breast cancer. These results could be compared with those of Sama et al. [22], which revealed a poor understanding and misperceptions of the risk factors, signs/symptoms, prevention, and treatment. More than two-thirds of the respondents did not identify gender, increasing age, race/ethnicity and positive family history, first child at a late age, early menarche, late menopause, positive personal history, and nulliparity as potential risk factors. Knowledge gaps about risk factors have also been reported elsewhere among the general population $[17,23]$ : university students in Angola [24], female medical students in Saudi Arabia [25], nurses in Pakistan [26], and female teachers in Malaysia [27] and Kuwait [28].
With regard to misperceptions, $26.9 \%$ of participants cited witchcraft as a risk factor of breast cancer. This is in line with a community survey in semi-urban Cameroon [29], studies on rural women [30] and market women [31] in Ibadan, Nigeria, and female medical students in Ethiopia [19], suggesting that women still attribute the occurrence of breast cancer to a mystical origin. Among others, they considered it "a spiritual attack", "God's curse", and "attack from the enemy". This observation was not that different from reports in a more developed setting: female teachers in Saudi Arabia attributed breast cancer to God and a belief in the evil eye [32], while 96.8\% of Arab-speaking women in Qatar attributed its occurrence to fate/destiny, and less than one-fifth to Gods' punishment and bad luck [33].

The major contribution of media in educating the public regarding breast cancer observed in this study has also been reported by other researchers from Saudi Arabia [32], Lebanon [34], Nigeria [35], and Iran [18]. This demonstrates the need to pay greater attention to this source of information to ensure that the correct information reaches the target population.

\section{Conclusion}

In conclusion, this study has shown that participants of this resettlement colony have poor knowledge about breast cancer, be it about risk factors, signs, and symptoms, or early detection procedures, where the overall knowledge score was only $18.8 \%$. Therefore, it is important to create awareness, educate the community, and remove the misconceptions associated with ignorance through community-based educational/ awareness campaigns. Educating health care workers is also a very important aspect. We also have to keep in mind that media exclusively will not be enough; information needs to be disseminated in a form which is appealing to the community.

\section{Compliance with Ethical Standards}

Ethical Considerations The official ethical clearance was obtained from the King Khalid University Ethical Committee; the private information of the students was used for research only. 
Administrative Considerations The researchers fulfilled all the required official approvals.

\section{References}

1. Gilani SI, Khurram M, Mazhar T, Mir ST, Ali S, Tariq S et al (2010) Knowledge, attitude and practice of a Pakistani female cohort towards breast cancer. J Pak Med Assoc 60:205-208

2. Ferlay J, Soerjomataram I, Ervik M, Dikshit R, Eser S, Mathers C et al (2013) GLOBOCAN 2012 v1.0, Cancer incidence and mortality worldwide: IARC CancerBase no. 11 [internet]. International Agency for Research on Cancer, Lyon

3. Mokdad AH, Jaber S, Aziz MI, AlBuhairan F, AlGhaithi A, AlHamad NM et al (2014) The state of health in the Arab world, 1990-2010: an analysis of the burden of diseases, injuries, and risk factors. Lancet 383(9914):309-320

4. Lozano R, Naghavi M, Foreman K, Lim S, Shibuya K, Aboyans V et al (2012) Global and regional mortality from 235 causes of death for 20 age groups in 1990 and 2010: a systematic analysis for the global burden of disease study 2010. Lancet 380(9859):2095-2128

5. Saudi Cancer Registry (n.d.) Available: http://www.scr.org.sa/?module= publications\&page=list\&id=46\&page_num=1. Accessed 7 Nov 2014

6. Ibrahim EM, Zeeneldin AA, Sadiq BB, Ezzat AA (2008) The present and the future of breast cancer burden in the Kingdom of Saudi Arabia. Med Oncol 25:387-393. https://doi.org/10.1007/s12032-008-9051-5

7. Dündar PE, Ozmen D, Oztürk B, Haspolat G, Akyildiz F, Coban S et al (2006) The knowledge and attitudes of breast self-examination and mammography in a group of women in a rural area in western Turkey. BMC Cancer 6:43

8. Balogun MO, Owoaje ET (2005) Knowledge and practice of BSE among female traders in Ibadan, Nigeria. Ann Ib Postgrad Med 3:52-56

9. Smith RA, Saslow D, Sawyer KA, Burke W, Costanza ME, Evans WP 3rd et al (2003) American Cancer Society guidelines for breast cancer screening: update 2003. CA Cancer J Clin 53:141-169

10. Seif NY, Aziz MA (2000) Effects of BSE training program on knowledge, attitude and practice of a group of working women. J Egypt Natl Cancer Inst 12:105-115

11. Salaudeen AG, Akande TM, Musa OI (2009) Knowledge and attitude to breast cancer and BSE among female undergraduates in a state in Nigeria. Eur J Soc Sci 7:157-165

12. Ceber E, Soyer MT, Ciceklioglu M, Cimat S (2006) Breast cancer risk assessment and risk perception on nurses and midwives in Bornova Health District in Turkey. Cancer Nurs 29(3):244-249

13. Othman A, Ahram M, Al-Tarawneh MR, Shahrouri M (2015) Knowledge, attitudes and practices of breast cancer screening among women in Jordan. Health Care Women Int 36(5):578-592

14. Arevian M, Noureddine S, Abboud S (2011) Beliefs related to breast cancer and breast cancer screening among Lebanese Armenian women. Health Care Women Int 32(11):972-989

15. Mahfouz AA, Hassanein MH, Nahar S, Farheen A, Gaballah II, Mohamed A et al (2013) Breast cancer knowledge and related behaviors among women in Abha city, southwestern Saudi Arabia. J Cancer Educ 28(3):516-520

16. Sarfo L, Dorothy A, Elizabeth A, Florence A (2013) Knowledge, attitude and practice of self-breast examination among female university students at Presbyterian University college, Ghana. Am J Res Communication 1(Suppl 11):395-404

17. Al-Dubai S, Qureshi A, Saif-Ali R, Ganasegeran K, Alwan M, Hadi J (2011) Awareness and knowledge of breast cancer and mammography among a group of Malaysian women in Shah Alam. Asian Pac J Cancer Prev 12:2531-2538

18. Montazeri A, Vahdaninia M, Harirchi I (2008) Breast cancer in Iran: need for greater women awareness of warning signs and effective screening methods. Asia Pac Fam Med 7(1):6

19. Ameer K, Abdulie S, Pal S, Arebo K, Kassa G (2014) Breast cancer awareness and practice of breast self-examination among female medical students in Haramaya University, Harar, Ethiopia. IJIMS. 2(2):109-119

20. Chioma C, Asuzu S (2007) Knowledge, attitude and practice of self-breast examination among the female students of the University of Ibadan, Nigeria. Pak J Soc Sci 4(Suppl 3):400-402

21. Somdatta P, Baridalyne N (2008) Awareness of breast cancer in women of an urban resettlement colony. Indian J Cancer 45(4):149

22. Sama CB, Dzekem B, Kehbila J, Ekabe CJ, Vofo B, Abua NL et al (2017) Awareness of breast cancer and breast self-examination among female undergraduate students in a higher teachers training college in Cameroon. Pan Afr Med J 28(1):164

23. Amin T, Mulhim A, Al Meqihwi A (2009) Breast cancer knowledge, risk factors and screening among adult Saudi women in a primary health care setting. Asian Pac J Cancer Prev 10(1):133-138

24. Sambanje M, Mafuvadze B (2012) Breast cancer knowledge and awareness among university students in Angola. Pan Afr Med J 11:70

25. Nemenqani D, Abdelmaqsoud S, Al-Malki A, Oraija A, Al-Otaibi E (2014) Knowledge, attitude and practice of breast self examination and breast cancer among female medical students in Taif, Saudi Arabia. Open Journal of Preventive Medicine 4(2):69-77

26. Ahmed F, Mahmud S, Hatcher J (2006) Breast cancer risk factor knowledge among nurses in teaching hospitals of Karachi, Pakistan: a cross-sectional study. BMC Nurs 19:5-6

27. Parsa P, Kandiah M, Mohd ZN (2008) Knowledge and behavior regarding breast cancer screening among female teachers in Selangor, Malaysia. Asian Pac J Cancer Prev 9(2):221-227

28. Alharbi N, Alshammari M, Almutairi B, Makboul G, El-Shazly M (2012) Knowledge, awareness, and practices concerning breast cancer among Kuwaiti female school teachers. Alexandria Journal of Medicine 48(1):75-82

29. Suh M, Atashili J, Fuh E, Eta V (2012) Breast self-examination and breast cancer awareness in women in developing countries: a survey of women in Buea, Cameroon. BMC Res Notes 5:627-632

30. Oluwatosin $\mathrm{O}$ (2006) Rural women's perception of breast cancer and its early detection measures in Ibadan, Nigeria. Cancer Nurs 29(6):461-466

31. Oladimeji K, Tsoka-Gwegweni J, Igbodekwe F, Twomey M, Akolo C, Balarabe H (2015) Knowledge and beliefs of breast selfexamination and breast cancer among market women in Ibadan, south west, Nigeria. PLoS One 10(11):e0140904

32. Dandash K, Al-Mohaimeed A (2007) Knowledge, attitudes, and practices surrounding breast cancer and screening in female teachers of Buraidah, Saudi Arabia. Int J Health Sci (Qassim) 1(1):61-71

33. Donnelly T, Khater A, Al-Bader S, Kuwari M, Al-Meer N, Malik M et al (2013) Beliefs and attitudes about breast cancer and screening practices among Arab women living in Qatar: a cross-sectional study. BMC Womens Health 13:49

34. Kobeissi L, Hamra R, Samari G et al (2012) The 2009 Lebanese National Mammography Campaign: results and assessment using a survey design. Epidemiol. 2:112. https://doi.org/10.4172/21611165.1000112

35. Kayode FO, Akande TM, Osagbemi GK (2005) Knowledge, attitude and practice of breast self examination among female secondary school teachers in Ilorin, Nigeria. Eur J Sci Res 10(3):42-47

Publisher's Note Springer Nature remains neutral with regard to jurisdictional claims in published maps and institutional affiliations. 